\title{
EL PENSAMIENTO DE JOSEP LLUÍS SERT RESPECTO AL ARTE DE GRAN FORMATO EN LA OBRA DE JOAN MIRÓ, SU RELACIÓN CON LOS ESPACIOS PÚBLICOS Y LA ARQUITECTURA *
}

René García **

Pareja de enamorados de los juegos de flores de almendro (Fragmento) Joan Miró, La Défense, París, 1975

Fuente: Archivo suministrado por el autor

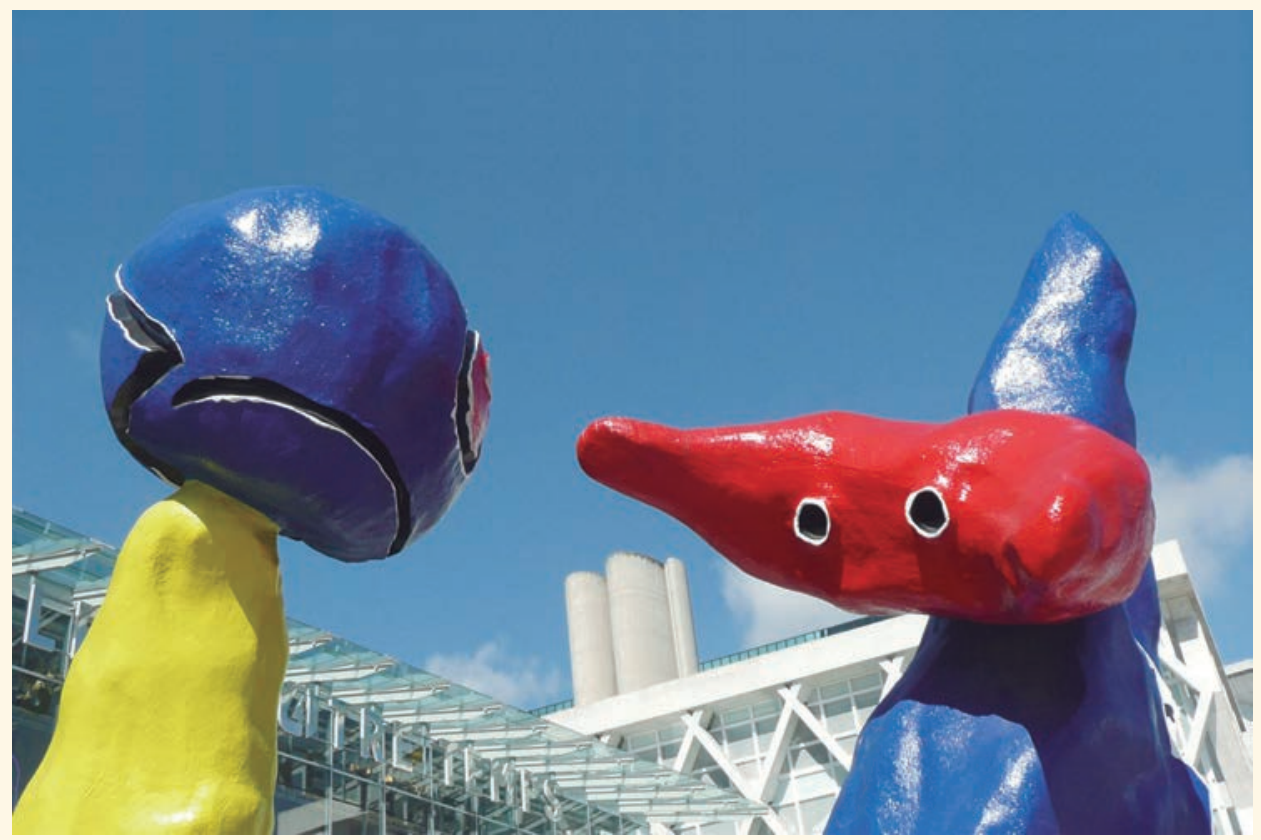

\section{RESUMEN}

Que los arquitectos hablen de arte no es algo nuevo, si se tiene en cuenta una de las características principales de la arquitectura, la potencialidad de su materia construida para ser interpretada estéticamente, para ser teorizada, criticada -con mayor o menor acierto- . Lo ya no tan común es hacerlo con la solvencia intelectual del protagonista de primera línea, con capacidad para teorizar y construir, a la vez, la historia del arte y la arquitectura.

Ese fue el caso excepcional de Josep Lluís Sert, personaje indispensable para la comprensión del puzzle que significó la arquitectura y el arte moderno a uno y otro lado del Atlántico a lo largo de gran parte del siglo $X X$. El conocimiento profundo fruto de su amistad y trabajo durante décadas, codo a codo con el artista universal Joan Miró, le convierten en la persona indicada para expresar su opinión sobre uno de los temas comunes que más les apasionaba y en el que coincidían de una manera casi unánime: la imperiosa necesidad de unir arquitectura, arte y paisaje como parte de un todo armónico, que ayudara al hombre moderno a vivir sus ciudades de una manera más alegre y confortable, eso sí, enganchado a la tierra con sus raíces mediterráneas como los algarrobos y olivos que tanto le gustaba pintar a Miró.

La comprensión por parte de Sert del arte de gran formato -en algunos casos monumental- de la obra Mironiana fue profunda y consciente, sus colaboraciones en proyectos se hicieron cada vez más intensas y fructíferas, por ello, cuando Sert hablaba del personaje y la obra de Joan Miró, hablaba con la voz de quien tiene la autoridad, del que conoce las verdades que él mismo ha ayudado a edificar. La intención de estas líneas es la de asomarse a un extenso y rico paisaje construido por estos dos personajes fundamentales, que sirva para hacerse una idea del interés que puede llegar a tener en los procesos creativos las interrelaciones entre el arte y la arquitectura.

\section{PALABRAS CLAVE}

Pintura mural, Escultura monumental, Tratamiento paisajístico, Esculturas en arquitectura, Josep Lluis Sert, Joan Miró 


\section{THE THOUGHT OF JOSEP LLUÍS SERT REGARDING THE ART OF GREAT FORMAT IN THE WORK OF JOAN MIRÓ, ITS RELATION WITH PUBLIC SPACES AND ARCHITECTURE}

René García ***

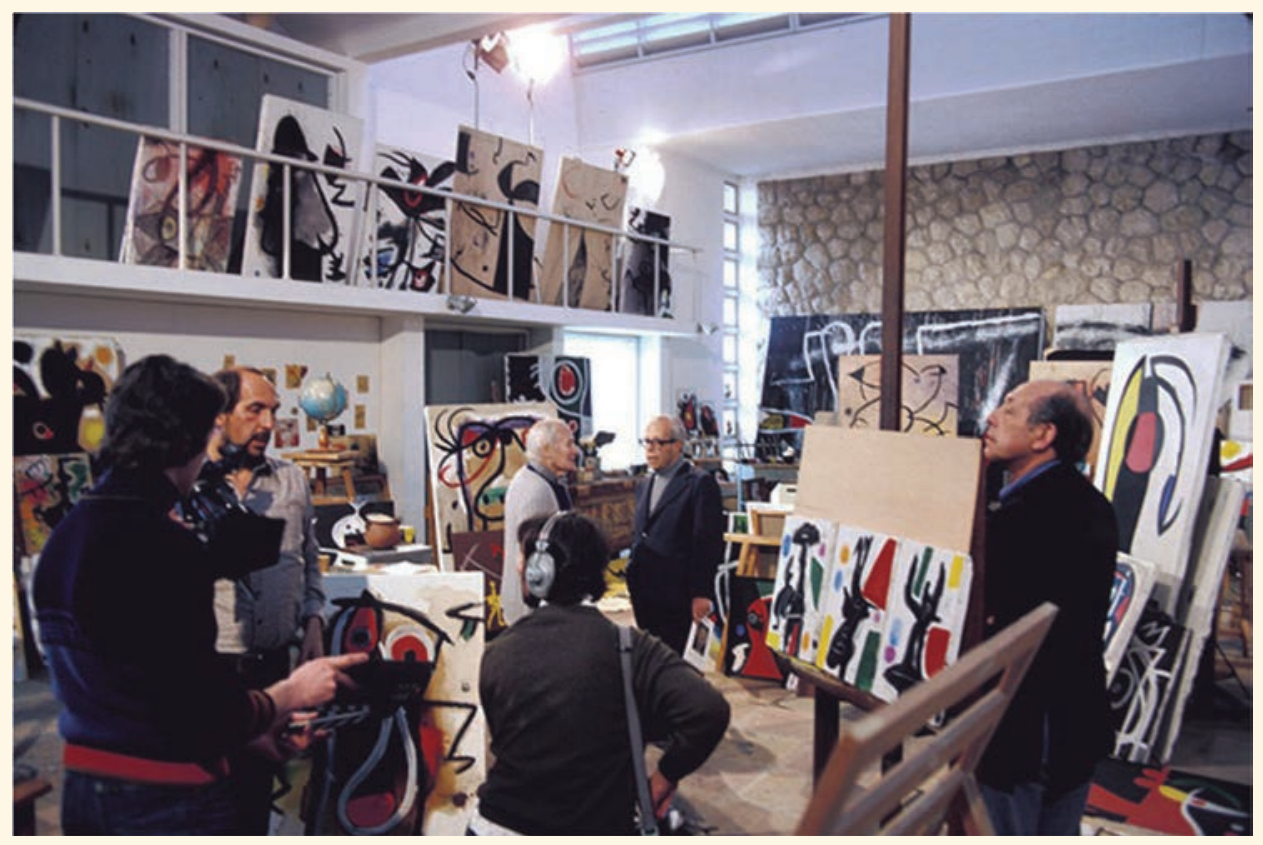

* Arquitecto, candidato a Doctor en el departamento de Proyectos Arquitectónicos de la Universidad Politécnica de Cataluña de Barcelona y D.E.A en estudios avanzados de investigación otorgado por el mismo departamento. Ha llevado a cabo su labor profesional en la última década en diversos despachos de arquitectura y empresas constructoras en España, compaginándola con el trabajo investigativo en la academia. Desarrolla actualmente su trabajo de investigación entre La Fundación Miró de Barcelona y la Biblioteca Kandinsky del centro George Pompidou en Paris

Recibido: 17 de enero de 2011 Aprobado: 4 de abril de $201 \mathrm{I}$

\begin{abstract}
That the architects speak of art is not new, considering one of the main features of the architecture, the potential of his subject aesthetically built to be interpreted to be theorized, criticized - with varying success. What is not so common to do with the intellectual solvency of the protagonist of the first line, and build capacity for theorizing both art history and architecture. That was the exceptional case of Josep Lluís Sert, character essential to understanding the puzzle meant architecture and modern art on either side of the Atlantic throughout much of the twentieth century. Deep knowledge fruit of their friendship and work for decades, side by side with the universal artist Joan Miró, make him the right person to express their views on one of the most common themes that were passionate and in a way that matched almost unanimous: The urgent need to unite architecture, art and landscape as part of a harmonious whole, to help modern man to live their cities in a more cheerful and comfortable, That If hooked to earth with their Mediterranean roots as carob and olive trees he loved painting. Understanding by Sert large format art -sometimes monumental- Miró's work was profound and consent, their collaborative projects became increasingly intense and fruitful, so when talking about the character and Sert the work of Joan Miró, spoke with the voice of one who has the authority, which knows the truth that it has helped to build.

The intent of these lines is to look into a vast and rich landscape built by the two main characters, serving to get an idea of interest can have on the creative process interrelationships between art and architecture.
\end{abstract}

\section{KEYWORDS}

Mural painting, Monumental sculpture, Landscape treatment, Sculptures in architecture, Josep Lluis Sert, Joan Miró
Miró y el Arquitecto Sert en el estudio del artista en Mallorca

Fuente: Archivo suministrado por el autor 


\title{
De la pintura Mural al arte público de gran formato
}

\author{
(...) El mundo de Joan Miró es un constante buscar y descubrir, sus intereses van de \\ los objetos más minúsculos a los mayores espacios, abarcando un mundo ilimitado \\ de cuyas relaciones es especialmente consciente (...)
}

De esta manera, precisaba Josep Lluís Sert' ${ }^{\prime}$ la magnífica capacidad para analizar e intervenir en el espacio físico y de las ideas, quien fue además de íntimo amigo, uno de sus principales compañeros de viaje por la historia de la arquitectura y el arte del siglo $X X$.

En uno de los borradores de sus manuscritos titulado Un nuevo planteamiento de la pintura mural ${ }^{2}$ donde explica, entre otros temas, la obra pública en gran formato de Joan Miró, el arquitecto Barcelonés -destaca especialmente- la capacidad del pintor para reinventarse la pintura mural transgrediendo los límites, las convenciones técnicas y artísticas trazadas hasta ese momento. Miró que ya había intentado en sus años parisinos "asesinar la pintura" supera los límites de la pintura de caballete y se atreve con obras de gran formato.

Sert subraya que para la mayoría de los pintores la alianza entre pintura y arquitectura se fundamenta en la absorción y mimetización de la obra pictórica dentro de la arquitectura por un lado, y por otro, de la creación de una arquitectura propia, como el caso de los efectos «trompe-l'oeil» o trampantojos de los murales de il Veronese en villas renacentistas como la Maser de Andrea Palladio.

El marco del cuadro -tradicionalmente rectangular- define el límite físico de la obra artística, en el caso de pinturas o mosaicos de gran formato en zonas públicas de las ciudades, este marco puede tener diversas formas, pero habitualmente se presentan como superficies similares a las de una pintura de caballete ampliada que encaja en una gran pared. Son estos resquicios, estas zonas intersticiales rutinarias entre la obra mural y la arquitectura las que Miró franquea.

Las primeras colaboraciones entre el artista y el arquitecto se dan mediados los años treinta en Barcelona y Paris, -Sert formaba parte del GATEPAC ${ }^{3}$ y del ADLAN ${ }^{4}$ - e invitan

I JOSEP LLUIS SERT (Barcelona España 1902 - 1983) arquitecto Español de origen Catalán y familia relacionada con el mundo del arte - su tío fue el pintor y reconocido muralista Josep María Sert i Badia- Graduado como Arquitecto del La ETSAB de Barcelona en (1929), formó parte del GATEPAC (1930-36), viajó a París a trabajar en el despacho de Le Corbusier y Pierre Jeanneret, con quienes colaboró estrechamente en diversos proyectos que reinterpretaron en clave moderna la arquitectura tradicional mediterránea. Formó parte del CIAM del que llegó a ser presidente (1947), se exilia en los Estados Unidos a un mes de la caída de la república Española, allí son acogidas gratamente sus ideas como arquitecto y especialmente como urbanista, funda Town Planning Associates, posteriormente se incorpora a la Graduate school of Design de Harvard de la que llega a ser decano (1953). De su dilatada carrera como arquitecto y urbanista quedan numerosos y variados proyectos, pero cabe destacar en este caso las colaboraciones con diversos artistas y personajes del mundo del arte, como Joan Miró y Aimé Maeght, para quienes diseñó tres de los edificios más representativos de su carrera relacionados con el mundo del arte: el taller para el artista Miró en Mallorca (1954-57), La Fondatión Maeght en Saint-Paul-de-Vence (1964) y la Fundación Joan Miró Barcelona (1968-75).

2 AGUILÓ VICTORY, Magdalena, et al. “Miró Sert :Segons Ells Mateixos -En Sus Propias Palabras- In their Own Words: Correspondencia 1937-1980. "Murcia: Cendeac, 2008.

3 GATCPAC (1930-36)- Grupo de Arquitectos y Técnicos Catalanes Para la realización de la arquitectura Contemporánea- su actividad cultural y su compromiso social fueron más allá de la divulgación de sus ideas reformistas -fundaron la revista AC-, se convirtió en un grupo de influyentes técnicos que colaboró activamente con las instituciones de gobierno catalán en la república, especialmente en el ámbito de la vivienda social y los proyectos de planificación urbana a gran escala. Josep Torres Clavé, Antoni Bonet, Joan Baptista Subirana y Josep Lluís Sert, son sus principales impulsores, bajo la tutela de Le corbusier y con una activa participación de sus miembros en los CIAM, y un fuerte impulso a las ideas de una nuevo paisaje mediterráneo en la arquitectura moderna. el grupo se diluye por los acontecimientos acaecidos en el inicio de la guerra civil Española.

4 ADLAN (1932-36) “Los Amigos del Arte Nuevo " fue un grupo heterogéneo de seguidores y amantes del arte de vanguardia en la Cataluña de los años treinta, en el que participaron profesionales liberales, comerciantes e incluso empresarios, dentro de cuyos objetivos se encontraba promover lo que ellos mismos en uno de sus eslóganes denominaron " salvar lo que hay de vivo dentro de lo nuevo y lo que hay de sincero dentro de lo extravagante", una clara alusión a la tutela del movimiento surrealista que les hermanaba. Sus principales animadores fueron, Joan Prats, Joaquim Gomis y Josep Lluís Sert, entre los personajes nacionales que colaboraron con el grupo destacaron, J.V. Foix, Sebastià Gasch, Lluís Montanyà y Magí A. Cassanyes, de carácter internacional como Paul Eluard, Hans Arp, Man Ray, los catalanes universales Salvador Dalí y el propio Joan Miró. 


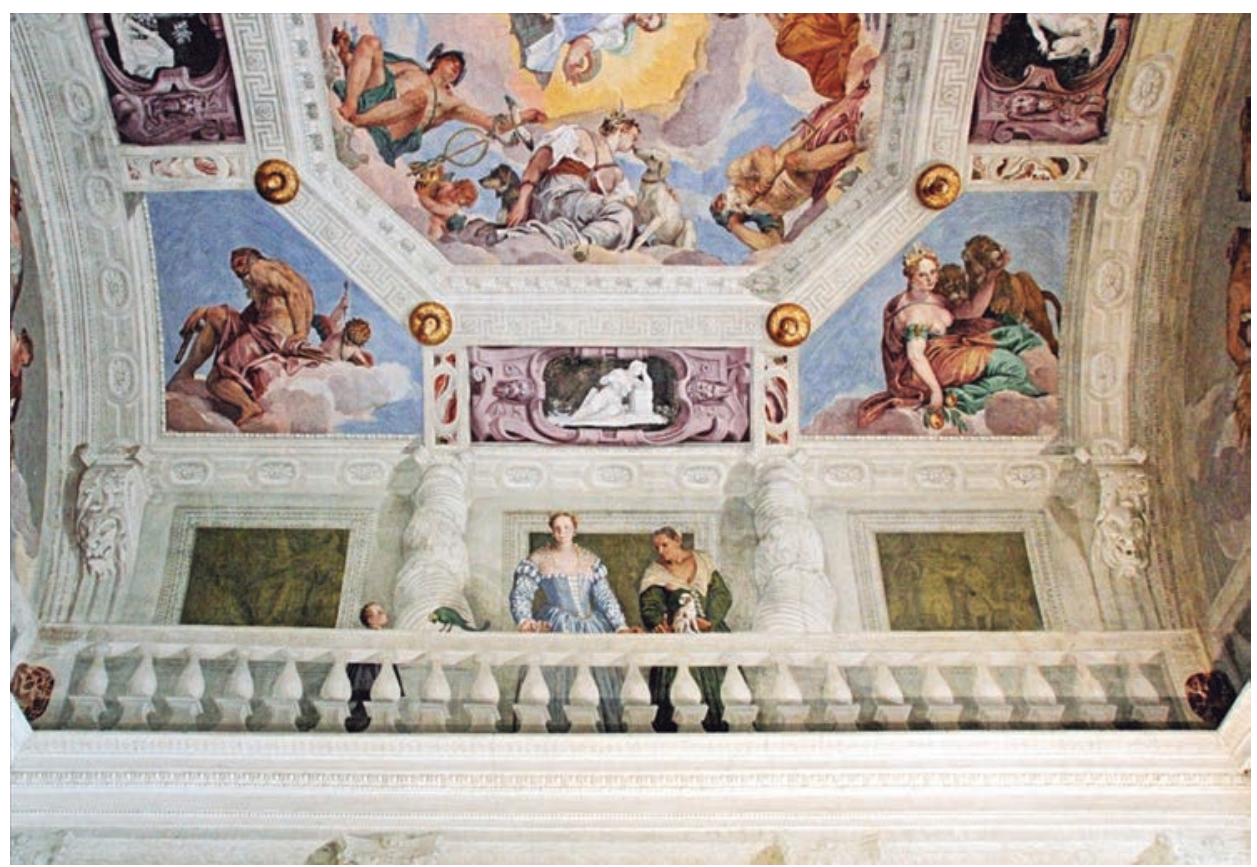

a Miró para que elabore una pequeña superficie mural del Saló dels Artistes Decoradors de Barcelona, allí el artista concibe sobre una superficie irregular de placa de fibrocemento una colorida y vivaz pintura que no ocupa en su totalidad el espacio del muro, pues deja partes del amianto vistas.
En el Pabellón de la Exposición Universal de París de 1937 diseñado por Sert, donde fueron expuestas, por primera vez, obras como el Guernica de Picasso, la Fuente de mercurio de Sandy Calder, la Montserrat de Julio González, o El pueblo español tiene un camino que conduce a una estrella de Alberto Sánchez, Miró pintó sobre el panel de doble altura del módulo de la escalera del pabellón, su Payes Catalá en revolta (Imagen 2) Campesino catalán en revolución- ${ }^{5}$ también conocido como El Segador, en este panel al igual que el de fibrocemento de Barcelona, deja sin cubrir completamente la superficie, sin rellenar los espacios que habitualmente la mayoría de pintores suelen apurar mediante trazos de fondos anodinos y que dan la impresión de ser espacios sobrantes en espera de la firma del artista.

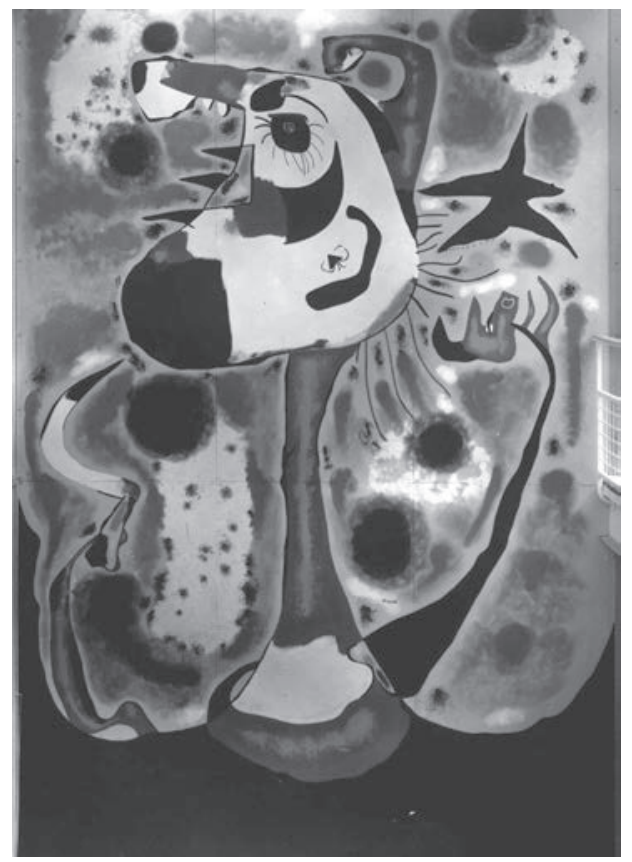

Del mural de Miró para la Expo de 1937, es conocida una anécdota de un marchante de arte quien al ver el mural con sus contornos irregulares, insinuó la necesidad de un marco pues le parecía inaudito una pintura sin límites precisos.

5 Este mural de grandes proporciones (hoy desaparecido) fue el primer trabajo en espacios arquitectónicos que compartió con Sert, Miró montado sobre un andamio realiza in situ un desgarrador y brutal despliegue de fuerza en el tema y la técnica empleada, en él encuentra la ocasión para dirigirse por primera vez a un público más amplio. Tardaría dos semanas en realizar esta monumental pintura que representa la rabia de un campesino catalán en protesta al yugo que le oprime.
Imagen I- Fragmento de:«trompe-l'oeil» Pintura mural, Paolo il Veronese,villa Maser, Andrea Palladio. Treviso Italia. (1560-70)

En esta imagen se puede observar el efecto óptico de engaño o Trampa ante el ojo -trampantojo- al que se refería Sert, donde la pintura genera un tipo de arquitectura propia, aunque ilusoria

Fuente: http://www.panoramio.com

Imagen 2. Joan Miró, Imagen del mural para e pabellón Español de la exposición de 1937, Payes Catalá en revolta. Fuente: Archivo Fundación Miró Barcelona. 
Imagen 3- Exterior de la Fundación Maeght, obra arquitectónica de Josep Lluís Sert, con diversas esculturas de artistas como Alexander Calder y Joan Miró.

La colaboración entre Miró y Sert fue amplia en tiempo - cercana a los 50 años- y prolífica en cuanto a cantidad y variedad de intervenciones y proyectos, al punto que fue justamente Sert quien atento a las sugerencias de Miró diseñó el Taller del artista en Mallorca y la Fundación de Barcelona que lleva su nombre. Esta profunda amistad queda reflejada en una abundante correspondencia epistolar, escritos, conversaciones y entrevistas, donde emergen diversidad de temas, entre ellos el de la pintura mural, como expresan las propias líneas escritas por Sert:

"He mantenido a menudo con mi amigo Joan Miró largas conversaciones sobre la pintura mural y su relación con la arquitectura, y he tenido el privilegio de colaborar en diversas ocasiones con él. Miró, quien habla menos pero piensa más que la mayoría de los pintores, ha concebido, según mi opinión, un nuevo planteamiento de la pintura mural que abandona la idea de los murales continuos, reemplazándola por un tratamiento mucho más lógico del muro mediante puntos focales" 6

Queda manifestado en otro de los textos de Sert titulado Joan Miró - pintor de grandes espacios - la importancia dada por el arquitecto y compartida por el pintor respecto a la integración de las artes con la arquitectura (Imagen 3 )

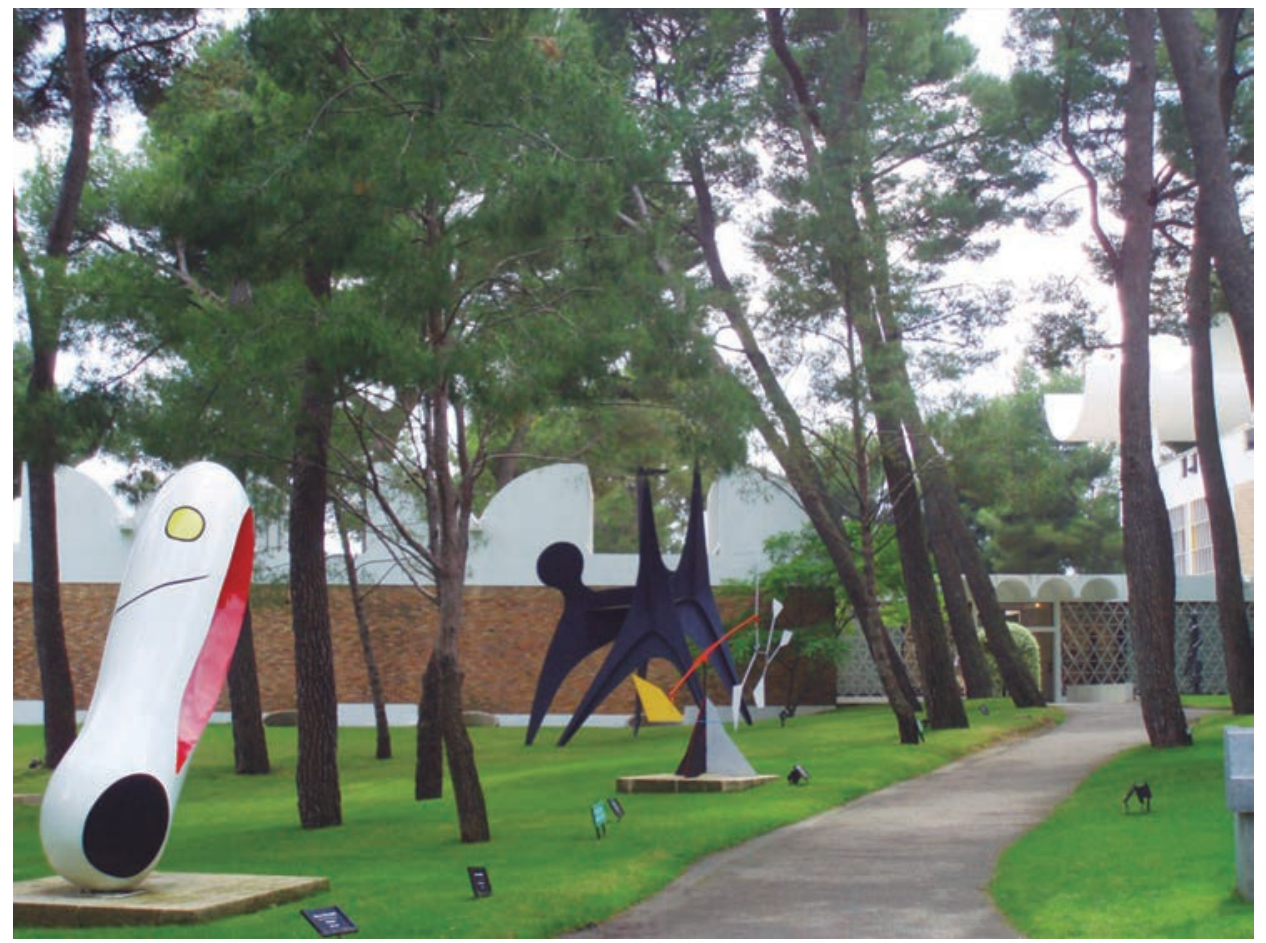

"El mejor fundamento para una auténtica integración entre pintura, escultura y arquitectura, se logra mediante el entendimiento entre el arquitecto y el pintor, el escultor o el pintor- Escultor. Este entendimiento presupone una comunidad de criterios, frecuentes intercambios de ideas, comunicación y amistad. Por parte

6 Respecto a la idea de elaborar los murales mediante puntos focales, Sert explica una anécdota de una visita a un encargo en Nueva York donde se le pedía a Miró hacer una intervención en un muro de veinte por veinte, debido a la forma de la sala el mural no podía contemplarse en su totalidad de una sola mirada, la propuesta de Miró fue crear diferentes puntos de atención "focales", que se relacionaban mutuamente contrastando colores y formas y conectándolas como si fuera una partitura musical. 
del pintor, ello requiere también un interés y una conciencia del espacio y de las relaciones espaciales, del comportamiento y naturaleza de los materiales y de sus texturas, y por último, pero no por ello menos importante, del tratamiento de la luz pues es gracias a la iluminación, natural o artificial, que todo lo visual cobra vida". ${ }^{7}$

Para Sert las pinturas que comparten lugar con los edificios modernos deben estar impregnadas de un mismo espíritu y están sujetas a la simbiosis resultante del trabajo compartido entre sus creadores, como pasaba cuando «las catedrales eran blancas» donde los arquitectos, los artesanos, pintores y escultores compartían ideas e ideales, trabajaban a mayor gloria de Dios y permanecían cerca del pueblo, convivían en ellas las representaciones más sencillas y realistas con los más oscuros símbolos en espacios que albergaban altares muros o vitrales.

Por ello, no es extraño la alta valoración que tiene Sert de la figura y la obra de Miró - más allá de su amistad - que se convierte con los años en admiración - sabe la envergadura y la trascendencia del trabajo visionario emprendido por el artista catalán, sabe que es en esa esencia de las cosas sencillas, casi anónimas ${ }^{8}$, donde reside el carácter innovador de su arte nuevo que años después encantará al mundo entero:

(...) Su actitud frente a la pintura se asemeja en muchos sentidos a la de un viajero del espacio. Su mayor aportación consiste no sólo en lo que incluye en el lienzo, sino en lo que deja fuera. Los espacios abiertos entre zonas pintadas, los silenciosos vacíos, son lo mejor de algunas de sus pinturas. Su aguda mirada le permite como a nadie establecer la verdadera relación entre los objetos más dispares (de la más variada índole) situándolos en el sitio justo y a la distancia justa. Dadle un montón de trastos viejos y no tardarán en cobrar vida convertidos en un Miró. ${ }^{9}$

En una carta fechada en $1968^{10}$ donde Miró se dirige a Sert, le pone al corriente, entre otros temas, de los pormenores sobre el encargo del ayuntamiento de la ciudad de Barcelona para ejecutar un mural monumental en las instalaciones del aeropuerto del Prat - lugar donde se ubica el aeropuerto de la ciudad condal- en ella Miró comenta: “ Me han encargado un mural de $50 \times 10$ m para el aeropuerto, de emplazamiento exterior, de manera que sería lo primero que verían los viajeros de los vuelos internacionales y podría considerarse como bienvenida". Y prosigue con el relato [...] "Al dar la bienvenida a la gente por el aire se me ha ocurrido hacer lo mismo para los que llegan por tierra", refiriéndose al ofrecimiento hecho al alcalde de Barcelona para instalar una escultura monumental en bronce, cemento y cerámica para el Parque Cervantes de la misma ciudad.

Sert resalta la facilidad de Miró para moverse en intervenciones artísticas dentro de edificios o en espacios exteriores grandes, sin perder la conciencia de la escala, aclara cómo muchos escultores - sin tener en cuenta factores ambientales - intentan que sus obras se hagan "lo más grande que se pueda", pero como sucede con los negativos fotográficos algunas obras sólo pueden ser ampliadas hasta cierto tamaño, sin que parezcan desenfocadas o descontextualizadas. No es el caso de Miró que siempre encuentra la medida justa para dar sentido y carácter a su obra. (Imagen 4)

7 AGUILÓ VICTORY, Magdalena. Op cit p. 611.

8 La arquitectura Románica que Joán Miró pudo observar en sus años de formación, principalmente en el MNAC, Museo Nacional de Arte de Cataluña de Barcelona, fue una gran aportación a su estilo artístico en sus primeros años, allí descubrió el arte de la pintura mural, un arte anónimo sin nombres ni caras, sus connotaciones simbólicas y calidades espaciales de una sencillez y economía de medios que se ven reflejados en algunas de sus obras de los años veinte.

9 "Miró Peintures pour grand espaces" en Derriere le Miroir 128, Meght Éditeur, Paris (1961).

10 AGUILÓ VICTORY, Magdalena. Op cit p. 38I. 
Imagen 4- Joan Miró, Mujer y pájaro (1982) Parque de Joan Miró (o del Escorxador) Barcelona, en esta imagen se puede observar la escala monumental a la que llegó Miró a trabajar, sin perder el sentido de la escala

Fuente : $h$ ttp://www.panoramio.com

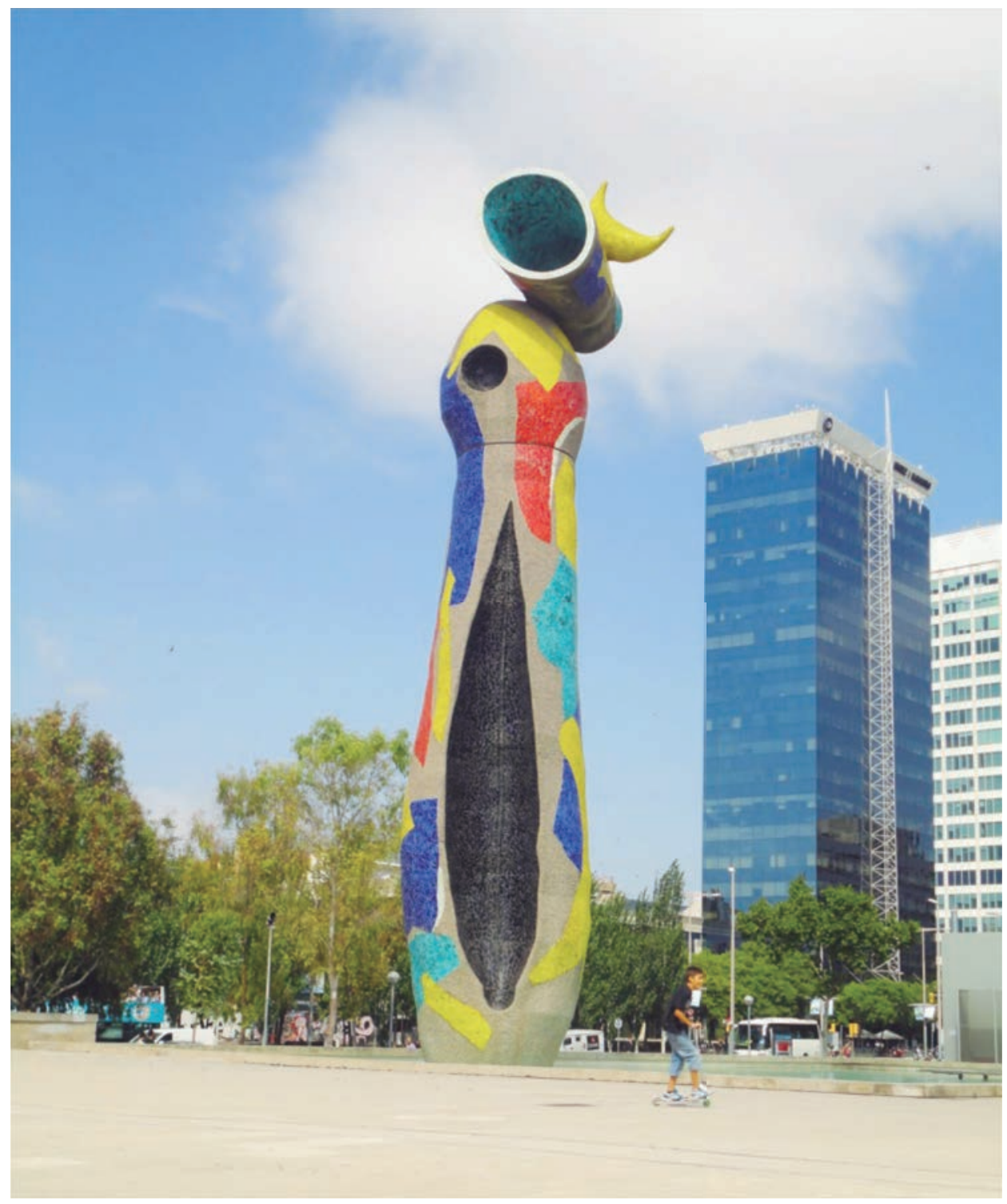

También destaca su facilidad para elaborar en pocas horas y con gran intuición, composiciones donde los objetos están ubicados en posiciones precisas y equilibradas que junto con los violentos y nítidos colores adquieren identidad propia:

[...] Este tipo de pintura puede aportar una gran vivacidad y animación a los espacios arquitectónicos, proporcionándoles puntos de tensión y contrapuntos visuales. Puede actuar a favor de la arquitectura moderna y no en su contra. Se trata de una concepción opuesta al tradicional camuflaje del renacimiento que cubría las estancias por completo; se trata de un no-mural. ${ }^{\prime \prime}$

\section{El arte anónimo y su integración con el paisaje:}

Sert compara el arte mural de Miró con las pinturas rupestres - de hecho Miró visitó Altamira con su colaborador Josep Llorens Artigas (Imagen 5) y hace una descripción de las sensaciones similares que le sugieren las grandes superficies iluminadas con antorchas en aquella 
época prehistórica donde las figuras según se avanzaba iban apareciendo y desapareciendo, algo similar sucede con los llenos y vacíos en la obra de Miró, a medida que se avanza por las monumentales superficies de sus murales - difícil de abarcar con sólo una mirada en algunos casos- toman vida y forma en un relato continuo que se antoja interminable.

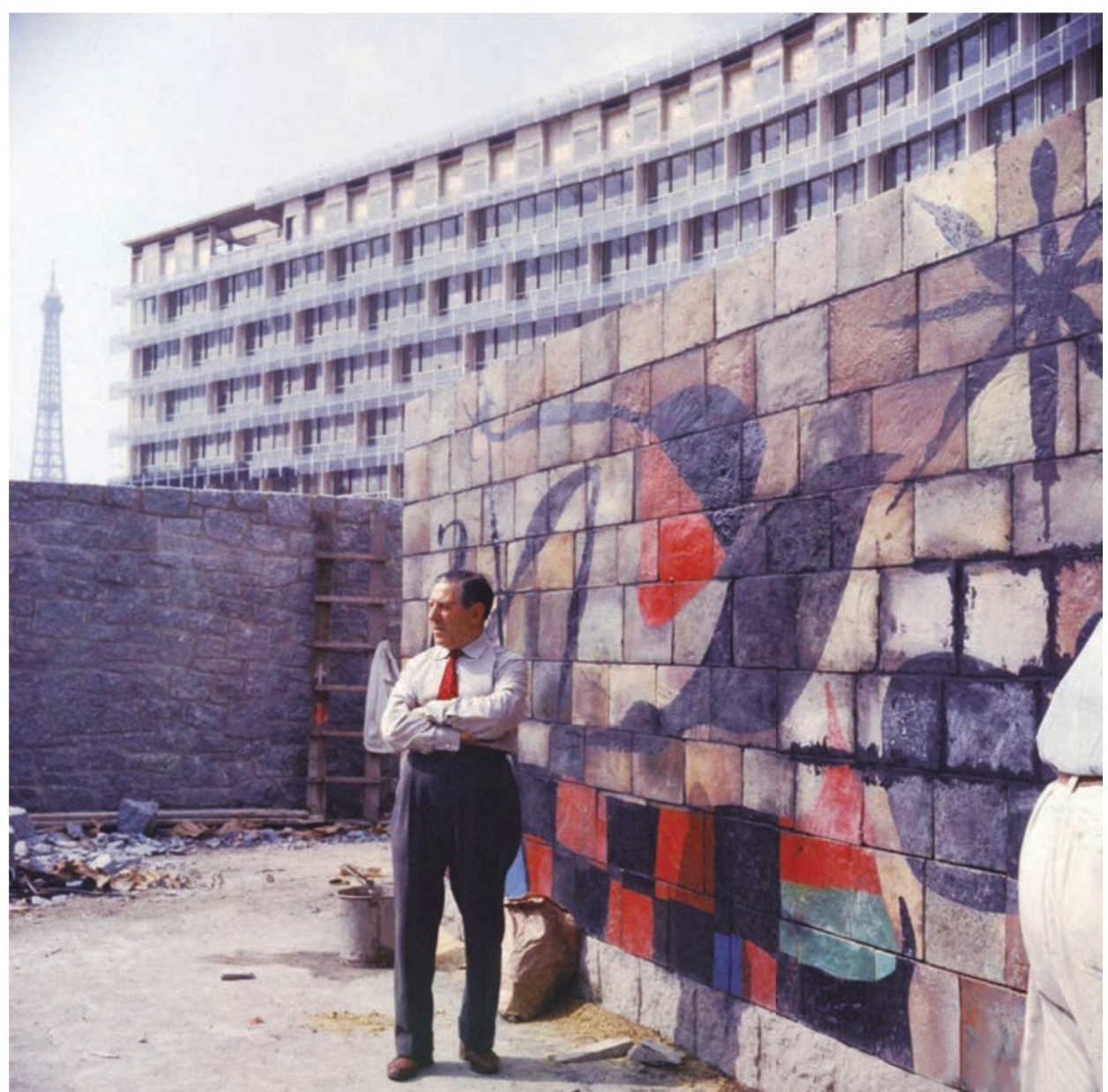

Referente a la escultura monumental en la obra de Miró, Sert aclara que la monumentalidad en su obra es diferente, desprovista de tópicos, de pomposidades, sin barreras entre la pintura y la escultura, resalta especialmente la cercanía de su obra al gran público, a las masas: "Miró puede convertir una plaza pública en un lugar más vivo y adecuado para múltiples situaciones, también puede tomar un pueblo mediterráneo y transformarlo en un lugar único en el que la gente conviva con sus obras, convirtiéndolas en parte de su vida cotidiana" 12

Sert reflexiona en sus escritos, sobre la decisión política de instalar obras de artistas modernos en espacios urbanos como zonas peatonales o islas animadas, y apuntan que las obras de Miró son las más indicadas para este tipo de lugares. Continúa su relato con una exaltación de la manera como Miró mediante un paisaje de bancales o muros a cielo abierto previamente organizado y distribuido para acoger sus obras, puede convertir ese lugar en un conjunto coherente cargado de belleza y sentido. (Imagen 6)
Imagen 5- Murales cerámicos del Sol y la Luna, (1958), Sede de la UNESCO en París. En esto imagen se observa a Jordi Artigas, estrecho colaborador de Miró y gran conocedor de la técnica cerámica

Fuente : Archivo Fundación Miró Barcelona

12 lbíd., p. 617. 
Imagen 6- Joan Miró, La "Fourche" del laberinto, Fundación Maeght en Saint Paul de Vence, 1963

Fuente : http://www.panoramio.com
Imagen 7- Joan Miró. Imagen de la escultura Personaje, la idea parte de una almendra (objecttrouve) que Miró transforma en una escultura. Jardines exteriores de la fundación Maeght. Bronze 1970

Fuente : http://www.panoramio.com
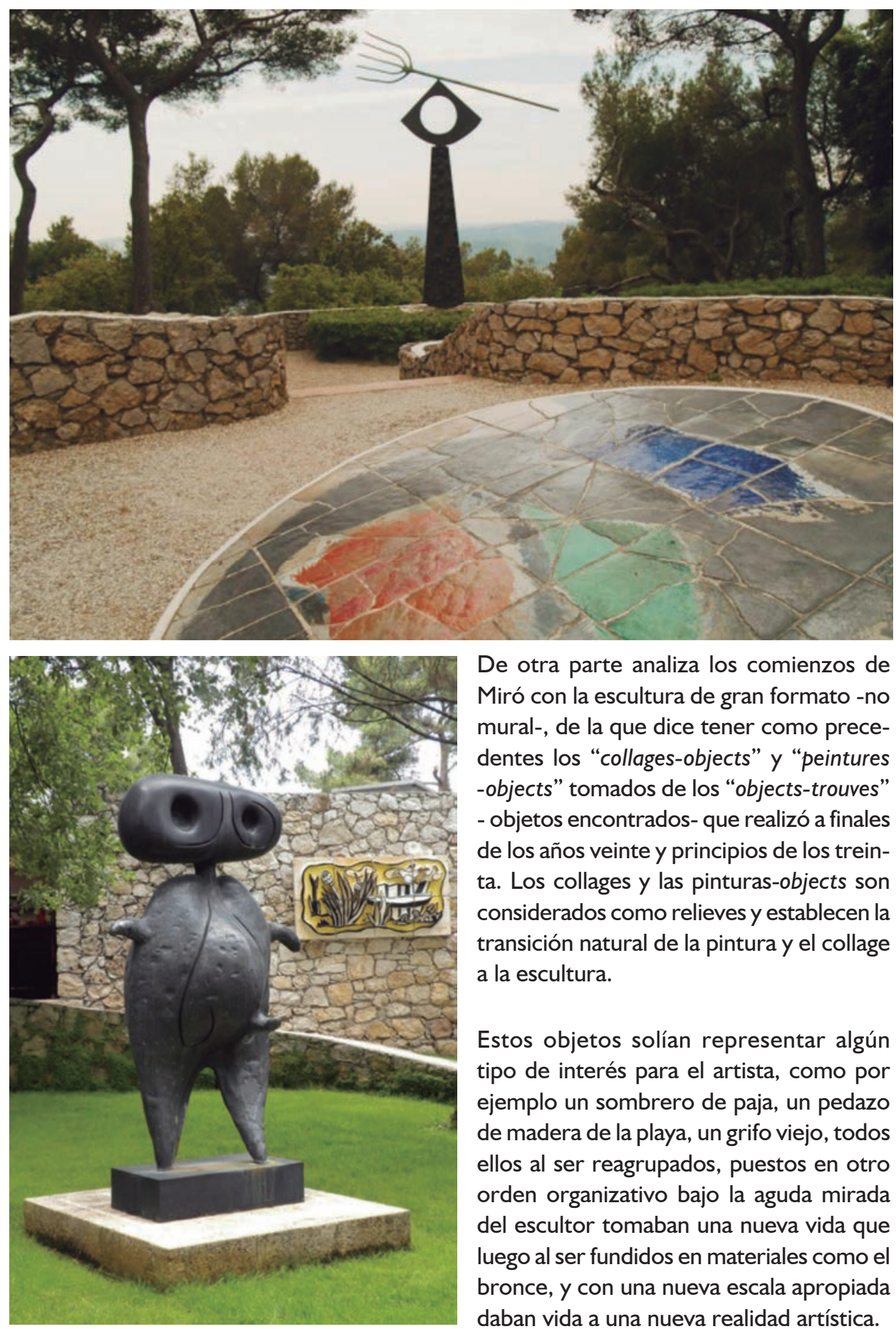

De otra parte analiza los comienzos de Miró con la escultura de gran formato -no mural-, de la que dice tener como precedentes los "collages-objects" y "peintures -objects" tomados de los "objects-trouves" - objetos encontrados- que realizó a finales de los años veinte y principios de los treinta. Los collages y las pinturas-objects son considerados como relieves y establecen la transición natural de la pintura y el collage a la escultura.

Estos objetos solían representar algún tipo de interés para el artista, como por ejemplo un sombrero de paja, un pedazo de madera de la playa, un grifo viejo, todos ellos al ser reagrupados, puestos en otro orden organizativo bajo la aguda mirada del escultor tomaban una nueva vida que luego al ser fundidos en materiales como el bronce, y con una nueva escala apropiada daban vida a una nueva realidad artística.

Hasta mediados de los años cuarenta fue cuando realmente logró una tridimensionalidad monumental en su obra -como la serie personnages y oiseaux -, sus maquetas de terracota se convierten en modelos para piezas más grandes, son concebidas en la mente del artista, quien piensa siempre en el entorno arquitectónico preciso donde será su emplazamiento, y tiene en cuenta las características paisajísticas del lugar. Son esculturas creadas para espacios que pueden ser cerrados o abiertos, ya sea patios, plazas públicas, jardines, calles o terrados. (Imagen 7) 
Los materiales utilizados por Miró para sus esculturas eran meticulosamente elegidos - solía ser parte de su metodología de trabajo la rigurosa planificación en contraste con su rápida y decidida ejecución - su histórico amplio repertorio de técnicas y texturas utilizados en el transcurso de los años, desde los inicios de su obra pictórica, los collages, su obra gráfica, hasta sus esculturas de pequeño y gran formato, dan una idea de la consciente riqueza que le infundió a su trabajo el artista.

Materiales tan variados y en algunos casos "humildes", como simples papeles y cartones, materiales de desecho, objetos encontrados de diversa índole y procedencia - madera, plástico, materiales naturales, metales-, reproducidos luego en modelos y maquetas de arcilla y cerámica, finalmente son fundidos en bronces policromados y revelan un panorama de la evolución y riqueza expresiva de su arte. Esta amplia gama de combinaciones de materiales y texturas aportan a los espacios arquitectónicos tan variados - escuelas, bibliotecas, parques, plazas, comercios, casas y edificios particulares - todo un rico universo de combinaciones.

Algo similar sucede con sus múltiples y amplias colaboraciones profesionales con otros artistas y artesanos, como señala a continuación el texto de Sert titulado "Esculturas en arquitectura" en referencia a uno de los proyectos más interesantes de su colaboración profesional conocido como el Laberinto - jardín urbano- de la Fondation Maeght en Saint Paul de Vence ${ }^{13}$. (Ver Imágenes 8, 9, 10)

En estos jardines, Miró pudo experimentar, con ayuda de los Artigas, padre e hijo, y del arquitecto, la manera de establecer un enfoque flexible que interrelacionara las esculturas con la arquitectura y con el tratamiento paisajístico del lugar, al trabajar con plantillas de tamaño natural de las diferentes piezas, toscamente realizadas en contrachapado. Las plantillas se trasladaban y recolocaban al tiempo que se iba decidiendo sobre el terreno el emplazamiento de los muros de contención, las escaleras y los estanques. De esta forma, se confrontaban y reunían todos los elementos antes de que adquirieran su forma definitiva. $[\ldots]^{14}$

Sert especifica en este texto, la similitud en la metodología empleada para diseñar el laberinto con la que habitualmente emplea Miró para componer y relacionar los elementos de su pintura, el fondo del lienzo en este caso fue sustituido por texturas de suelos, espacios vacios y vegetación controlada. Resalta además una de las referencias usualmente ineludibles para toda una generación de artistas y arquitectos Españoles y Catalanes, la obra de Antoni Gaudí, sobre la que comenta:

[...] El precedente más cercano a esta forma de trabajar la estableció Gaudí en el Parc Güell de Barcelona. Teniendo en cuenta la importancia de los espacios vacíos en la obra del artista (serían como los silencios en una composición musical), se puede establecer un paralelismo entre esculturas relacionadas y formas pictóricas relacionadas. ${ }^{15}$

Vale la pena resaltar además una carta de Miró dirigida a Sert y fechada en $1960^{16}$ en la que pregunta al arquitecto sobre el avance de la obras de la fundación Maeght, y de paso

13 La Fondatión Maeght se convirtió para Sert y Miró en una oportunidad única para poder experimentar algunas de las ideas comunes con respecto a la manera de entender e intervenir en el paisaje, allí se dio rienda suelta a la imaginación artística y la racionalidad arquitectónica dentro de un ambiente natural mediterráneo. En un entorno arquitectónico diseñado por Sert, colaboraron destacados artistas como Alexánder Calder, Alberto Giacometti, y el mismo Joán Miró. AGUILÓ VICTORY, Magdalena Op cit p. 629.

14 AGUILÓ VICTORY, Magdalena Op cit p. 629

15 Ibíd., p. 63I.

16 Ibíd., p. 29I. 
Imagen 8- Imagen exterior con los jardines la Fundación Maeght en Saint Paul de Vence. donde el arte, la arquitectura y el paisaje han sido meticulosamente estudiados e integrados

Fuente : http://www.panoramio.com

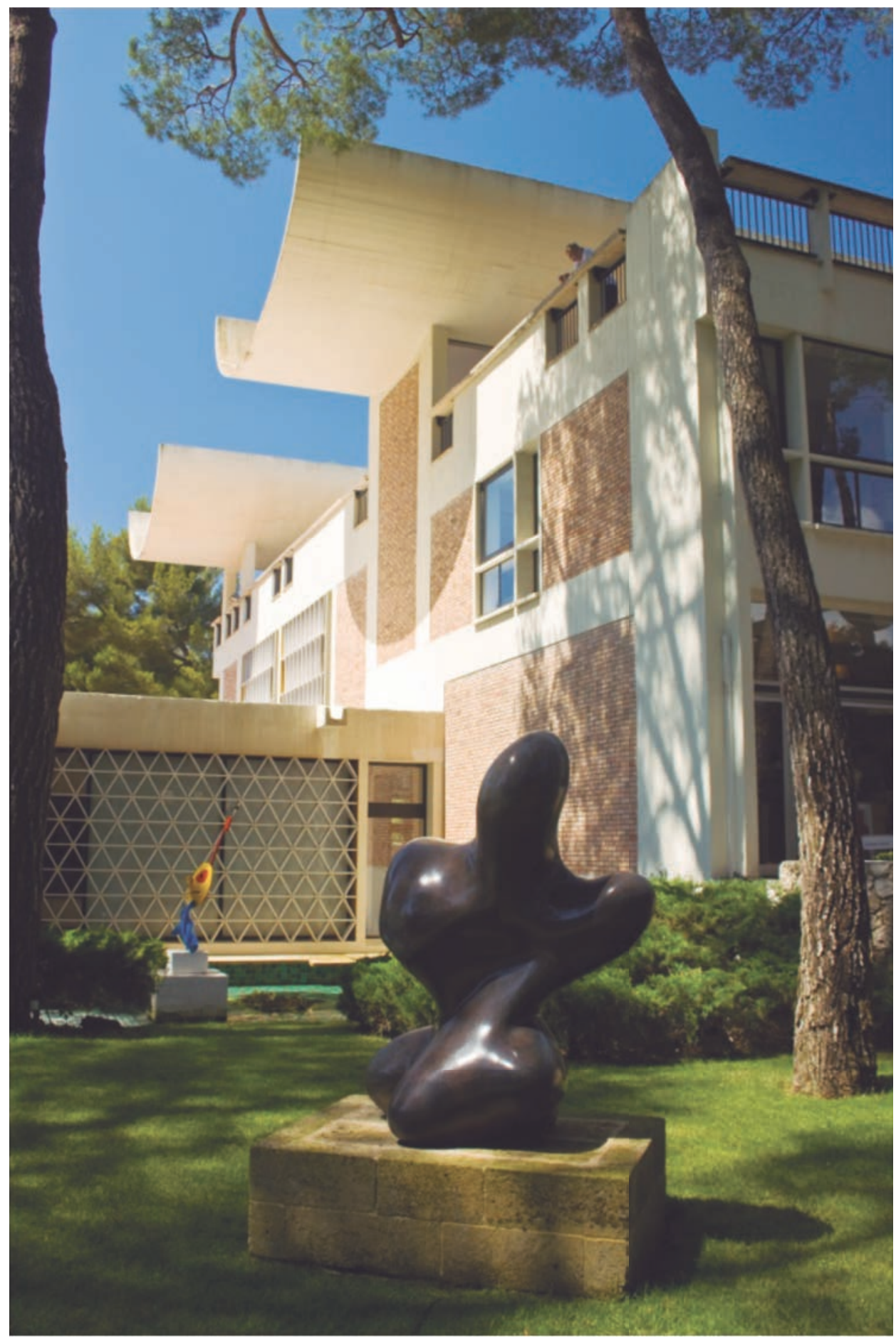



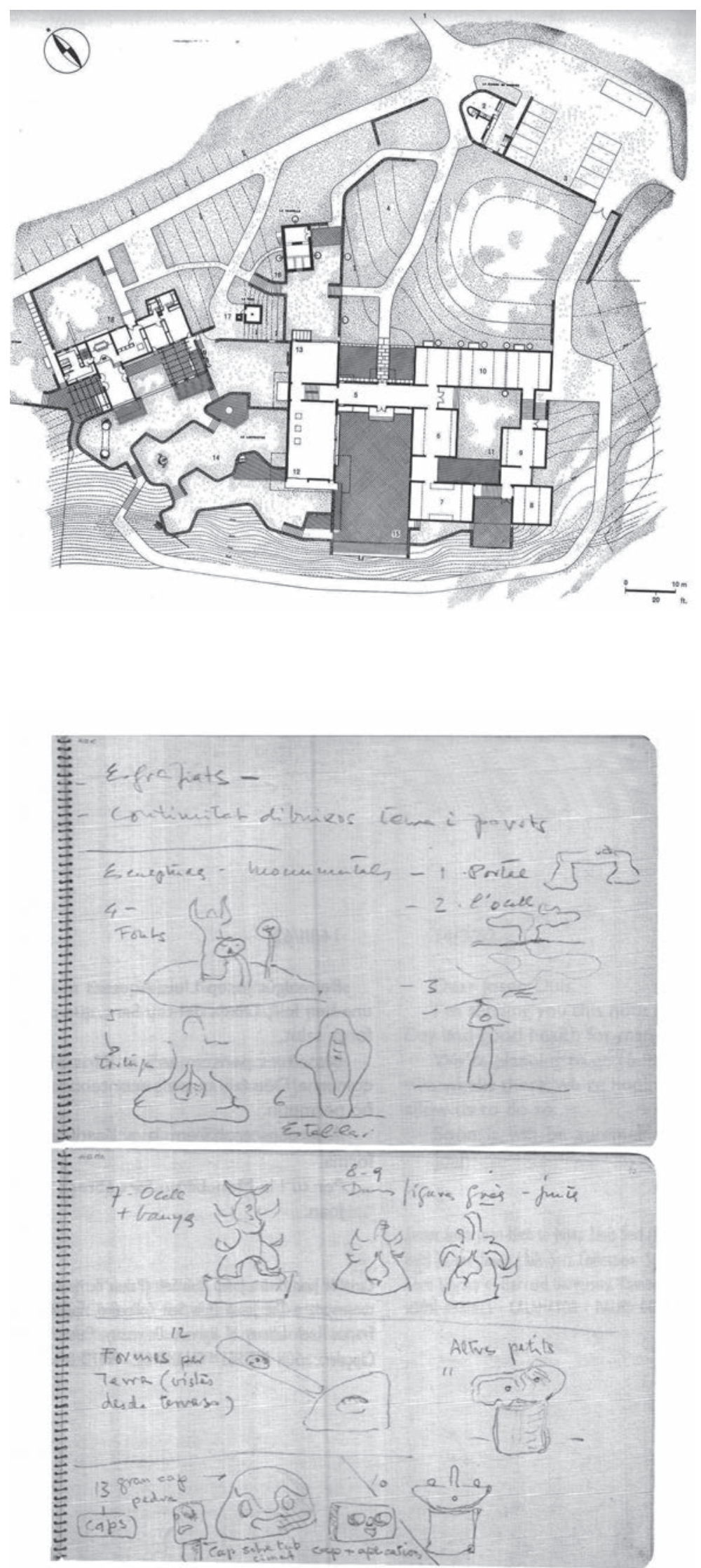

Imagen 9- Planta Baja Fundación Maeght en Saint Paul de Vence. se puede observar la distribución exterior de los jardines del laberinto diseñados por Sert en colaboración con otros artistas como Miró

Fuente : Archivo Fundación Miró Barcelona

Imagen 10-Bocetos (Sert) de algunas esculturas para el laberinto los jardines la Fundación Maeght en Saint Paul de Vence

Fuente : Archivo Fundación Miró Barcelona 
Imagen II- En esta imagen se puede ver al artista y el arquitecto charlando antes de una entrevista televisiva, dentro del estudio que diseño Sert para Miró en Mallorca

Fuente : http://www.panoramio.com

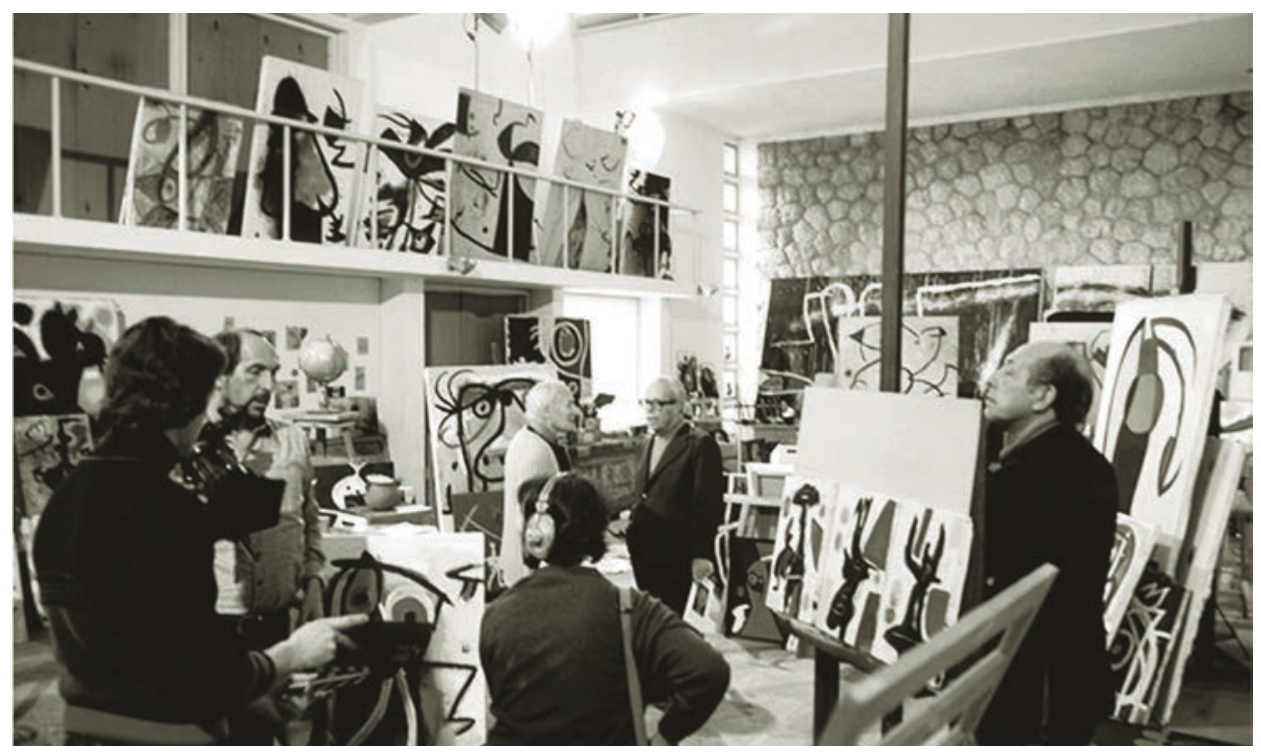

comenta sobre un dossier de trabajo que le fue facilitado y sobre el que ha estudiado la ubicación y recomposición de una serie de fragmentos para la construcción de algunos de sus objetos y esculturas, en ella Miró comenta:

"Habrá cosas de proporciones monumentales y arquitectónicas. independientemente de lo que haga por mi cuenta, hay cosas que me gustaría hacer en colaboración contigo, concebidas concretamente para la Fondatión, para el emplazamiento. Puedes ir pensando en ello [...] sobre todo lo que puede ser más apasionante, podríamos especular sobre nuevos materiales, como hacía Gaudí. Todo ello dictado por la arquitectura y el paisaje [... ${ }^{17}$

Destaca también, la humanidad, la jovialidad y a menudo el humor de sus esculturas, que cercanas al pueblo se asemejan a la "popularidad" de la obra Gaudiniana, es esa búsqueda lo que le ha llevado - en compañía con sus amigos artistas y amantes del arte- a concebir el Centro d'Estudis d'Art Contemporani de Barcelona, un espacio dentro de la ciudad, que quiere ir más allá del habitual museo y generar un lugar vivo para las nuevas generaciones de artistas, pero también para gente de todas las edades que se sientan atraídas por su obra artística y por el arte en general.

"Su obra puede y debe convivir con el pueblo. El día en que nuestras ciudades tengan parques limpios y seguros, en los que no se tenga prisa y uno pueda moverse con tranquilidad; cuando se reconozca que los ciudadanos tienen derecho a ese tipo de lugares, sean conscientes de ello y reclamen lo que durante tanto tiempo les ha sido negado, ese es un día que Miró lleva imaginando desde hace muchos años. En esos lugares sus obras podrán crecer de forma tan natural e informal como las plantas". ${ }^{18}$

7 lbíd.

18 lbíd., p. 635. 
Se recapitulan mediante las sabias palabras de Sert, buscar y descubrir, a eso dedicó incansablemente Joan Miró su vida Artística.

\section{CONCLUSIONES}

La colaboración entre arquitectos y artistas ha existido desde la antigüedad, aunque no siempre con la misma intensidad y en igualdad de condiciones. Hasta épocas recientes era el arte el que se acomodaba a la forma que la arquitectura le dictaba - especialmente en el arte de espacios interiores, en el arte de los jardines no lo era tanto- sin embargo, es justamente a finales del XIX principios del siglo $X X$, donde las vanguardias artísticas declaran su rebeldía a las convenciones de todo tipo y crean una interesante relación de contrapoder con la arquitectura, el artista plástico siente la libertad de explorar nuevos territorios, Miró formó parte de esa generación que quiso reinventar el arte y ese es justamente el objetivo de este documento, dejar constancia de esas nuevas relaciones entre artista y arquitecto, mostrar cuál fue durante una parte del siglo XX la manera de pensar, de trabajar, de colaborar entre estos dos personajes sobresalientes de su tiempo. Como es lógico la extensión del documento sólo deja vislumbrar un pequeño fragmento, el arte de gran formato, sin embargo son los procedimientos, los materiales, las técnicas empleadas, la metodología, las teorías planteadas, lo que ayuda a comprender globalmente un tema que a pesar de su aparente limitada aplicabilidad, puede encontrar en estas interesantes relaciones una verdadera función profesional y por tanto social.

\section{BIBLIOGRAFÍA}

AGUILÓ VICTORY, Magdalena, et al. Miró Sert: Segons Ells Mateixos = En Sus Propias Palabras = in their Own Words: Correspondencia 1937-1980. Murcia: Cendeac, 2008.

BALSACH, Maria-Josep. Joan Miró: Cosmogonías De Un Mundo Originario (1918- 1939). Barcelona: Galàxia Gutenberg, 2007.

MINGUET I BATLLORI, Joan M. Joan Miró: L’Artista i El Seu Entorn Cultural: (1918- 1983). Barcelona: Publicacions de l'Abadia de Montserrat, 2000.

MIRÓ, Joan, et al. Epistolari Català. Barcelona: Barcino, 2009.

MIRÓ, Joan; PRÉVERT, Jacquesand ÁLVAREZ GONZÁLEZ, Julio. Joan Miró: Pintures i Escultures 1949-1979. Exposición Mayo-Junio 1999: Centre Cultural Fontana d'Or De Caixa De Girona. Barcelona, 1998.

SERT, Josep L., 1902-1 983. Arquitectura De Sert En La Fundació Miró. Barcelona: Polígrafa, 1977. 